\title{
A rare manifestation of Neurofibromatosis type 1: A plexiform neurofibroma involving the mediastinum and lungs with endobronchial neurofibromata.
}

Running title: Plexiform neurofibroma involving the mediastinum.

\section{Authors:}

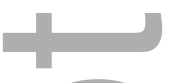

Dr Heather M. Pascoe ${ }^{1}$

Mr Phillip Antippa ${ }^{2}$

Associate Professor Louis Irving ${ }^{3}$

Dr Michael Christie

Dr Mark W. McCusker ${ }^{1}$

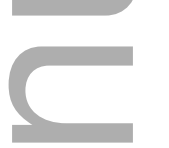

${ }^{1}$ Department of Radiology, Royal Melbourne Hospital, University of Melbourne, Parkville, Victoria, Australia.

${ }^{2}$ Department of Cardiothoracic Surgery, Royal Melbourne Hospital, University of Melbourne, Parkville, Victoria, Australia.

${ }^{3}$ Department of Respiratory Medicine, Royal Melbourne Hospital, University of Melbourne, Parkville, Victoria, Australia.

${ }^{4}$ Department of Pathology, The Royal Melbourne Hospital, University of Melbourne, Parkville, Victoria, Australia.

\section{Corresponding Author:}

Dr Heather Michelle Pascoe

Level 1 Radiology Department, Royal Melbourne Hospital, Grattan St, Parkville, Victoria, Australia, 3050

Email: pasoceh@gmail.com

Phone: 0438674141

Fax: 61393428369

This is the author manuscript accepted for publication and has undergone full peer review but has not been through the copyediting, typesetting, pagination and proofreading process, which may lead to differences between this version and the Version of Record. Please cite this article as doi: $10.1111 / 1754-9485.12802$

This article is protected by copyright. All rights reserved 
Article type : Radiology Case Report

6

7

8 A rare manifestation of Neurofibromatosis type 1: A plexiform

neurofibroma involving the mediastinum and lungs with endobronchial

neurofibromata.

Pascoe $\mathrm{HM}^{1}$, Antippa $\mathrm{P}^{2}$, Irving $\mathrm{L}^{3}$, Christie $\mathrm{M}^{4}$, McCusker $\mathrm{MW}^{1}$.

1. Department of Radiology, The Royal Melbourne Hospital, University of Melbourne, Parkville, Victoria, Australia.

2. Department of Cardiothoracic Surgery, The Royal Melbourne Hospital, University of

HM Pascoe: MBBS (Hons), BMedSci, MMed

P Antippa: MBBS, FRACS

L Irving: MBBS, FRACP

$M$ Christie: MBBS, FRCPA, PhD

MW McCusker: MB BCh, MRCPI, FFR(RCSI), FRANZCR

\section{Key words:}


Computed tomography, Endobronchial nodules, Lung, Mediastinal neurofibroma, Neurofibromatosis type 1, Plexiform neurofibroma

\section{Summary:}

Neurofibromatosis type 1 (NF1) is a multisystem phakomatosis. The intrathoracic manifestations of NF1 are protean. We describe a rare case of a plexiform neurofibroma infiltrating the mediastinum and lungs with multiple endobronchial neurofibromata. To our knowledge, a mediastinal plexiform neurofibroma extending into the lungs on CT has not been reported.

\section{Case Presentation:}

A 24-year-old male patient with known NF1, under surveillance for an optic nerve glioma, presented with right chest wall radicular pain. CT of the thorax demonstrated a right posterior mediastinal mass, likely the cause of his symptoms. In addition, CT identified a soft tissue mass in the mediastinum encasing the carina and left main bronchus (Figure 1a and $1 \mathrm{~b}$ ) and infiltrating into the lung parenchyma along the left upper and lower lobe bronchi (Figure $1 \mathrm{c}$ and $1 \mathrm{~d}$ ). There were also multiple nodules present within the trachea and bronchi on both sides (Figure 2).

Bronchoscopy confirmed multiple nodules within the trachea and both main bronchi (Figure 3) of which biopsies were taken. Histopathology demonstrated myxoid stroma and bland spindle cells which were S100 positive with scattered nerve fibres on neurofilament protein (NFP) staining, consistent with neurofibromata (Figure 4). There was no evidence of malignancy.

Fine needle aspirate of the mediastinal component yielded blood-stained fluid and mixed inflammatory cells only. No malignant cells were identified. However, given the infiltrative growth pattern and biopsy proven neurofibromata within the adjacent bronchi, this was favoured to represent a plexiform neurofibroma.

Surveillance imaging has been organised to monitor for growth of the endobronchial nodules and plexiform neurofibroma, as well as to monitor for potential malignant degeneration. 


\section{Discussion:}

Neurofibromatosis type 1 (NF1) is the most common phakomatosis occurring in approximately one in every 2000 births (1). It can be inherited in an autosomal dominant manner, however approximately $50 \%$ of cases occur sporadically due to a spontaneous mutation (1). NF1 involves multiple body systems with manifestations occurring in the thorax, abdomen, central nervous system, musculoskeletal system, and skin

Many intrathoracic manifestations of NF1 are recognised, including spinal and rib abnormalities, posterior mediastinal neurofibromata, cystic lung disease, pulmonary fibrosis, and intrapulmonary neurofibromata (1). Plexiform neurofibromata are pathognomic of NF1 and in the thorax, most commonly occur adjacent to ribs and in the paravertebral region $(1,2)$. Mediastinal plexiform neurofibromas are well described and occur in the distribution of the mediastinal nerves $(2,3)$. Bourgouin et al.(3) described four cases of mediastinal plexiform neurofibromata which involved the entire mediastinum in three patients and the middle and posterior mediastinum in one. A mediastinal plexiform neurofibroma infiltrating along the bronchi into the lungs however has not been previously described.

Endobronchial neurofibromata in NF1 are rare $(4,5)$. In a case report by Gillissen et al. (4), infiltration of the bronchial tree with neurofibromata was demonstrated on bronchoscopy and biopsy, however CT and MRI of the thorax were normal. In a case reported by Venugopal et al. (5), multiple nodular swellings within both main bronchi were neurofibromata on histology; additional intrapulmonary nodules were thought to represent intrapulmonary neurofibromata.

In this case, it is hypothesized that the soft tissue mass in the mediastinum and lungs is a plexiform neurofibroma given the infiltrating pattern and the presence of biopsy proven neurofibromata in the adjacent the airways. This is the first description of such an entity.

\section{References:}

This article is protected by copyright. All rights reserved 
84 (1) Rossi SE, Erasmus JJ, McAdams HP, Donnelly LF. Thoracic manifestations of

85

86

87

88

89

90

91

92

93

94

95

96

97

98

99

100

101

102

103

104

105

106

107

neurofibromatosis-1. AJR 1999 Dec;173(6):1631-1638.

(2) Tonsgard JH, Kwak SM, Short MP, Dachman AH. CT imaging in adults with neurofibromatosis-1: frequent asymptomatic plexiform lesions. Neurology 1998 Jun;50(6):1755-1760.

(3) Bourgouin PM, Shepard JO, Moore EH, McLoud TC. Plexiform neurofibromatosis of the mediastinum: CT appearance. AJR 1988 Sep;151(3):461-463.

(4) Gillissen A, Kotterba S, Rasche K, Müller K, Schultze-Werninghaus G. A rare manifestation of von Recklinghausen neurofibromatosis: advanced neurofibromatous infiltration in lung of a HIV-positive patient. Respiration 1994;61(5):292-294.

(5) Venugopal P, Karunakaran R, Bindu CG, Elizabeth. Intrabronchial neurofibromatosis. J Assoc Physicians India 2013 Sep;61(9):669-671.

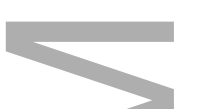

Figure Legends:

Figure 1: Coronal (A) and axial (B-D) CT thorax demonstrating a soft tissue mass in the mediastinum encasing the carina and left main bronchus (arrows in A and B) and infiltrating into the lung parenchyma along the left upper and lower lobe bronchi (arrows in $\mathrm{C}$ and $\mathrm{D}$ ).

Figure 2: Coronal (A) and sagittal (B) CT thorax demonstrates multiple nodules within the trachea (open arrow in A) and left sided bronchi (black arrows in A and B).

This article is protected by copyright. All rights reserved 
108 Figure 3: Bronchoscopy images demonstrating multiple nodules within the left main 109 bronchus.

110

111 Figure 4: Histopathology pictures of the bronchoscopy specimens (x200 magnification)

112 showed bland spindle cells with myxoid stroma (A). On immunohistochemistry, the

113 cells were positive for S100 (B). Appearances are consistent with neurofibromata.

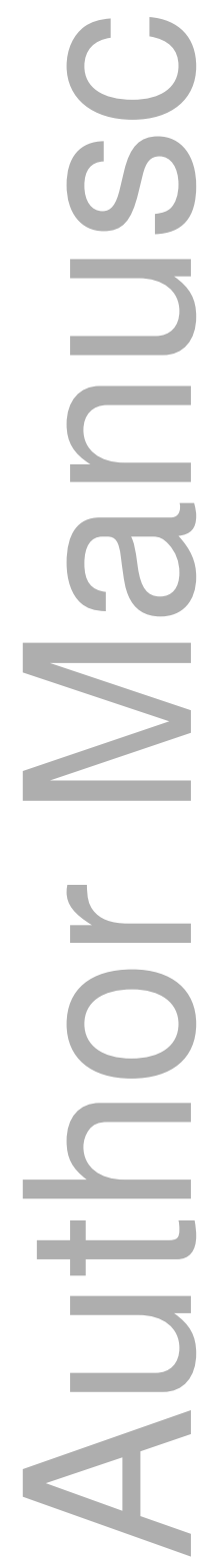

This article is protected by copyright. All rights reserved 

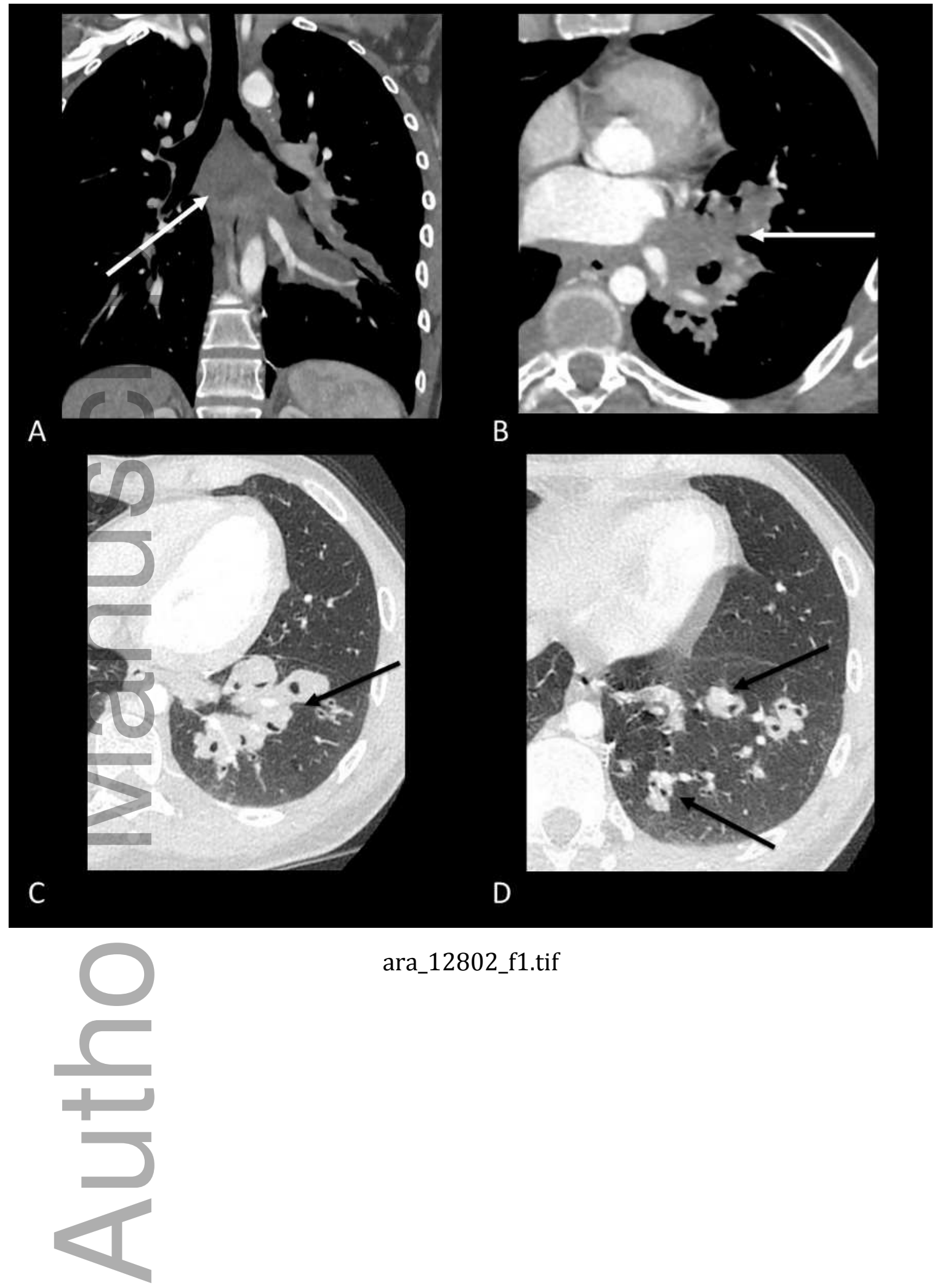

ara_12802_f1.tif

This article is protected by copyright. All rights reserved 


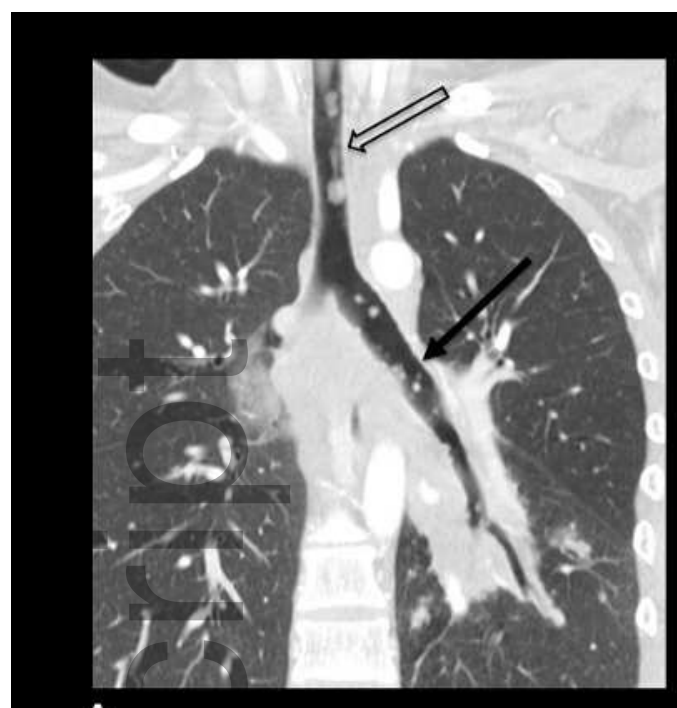

A

B
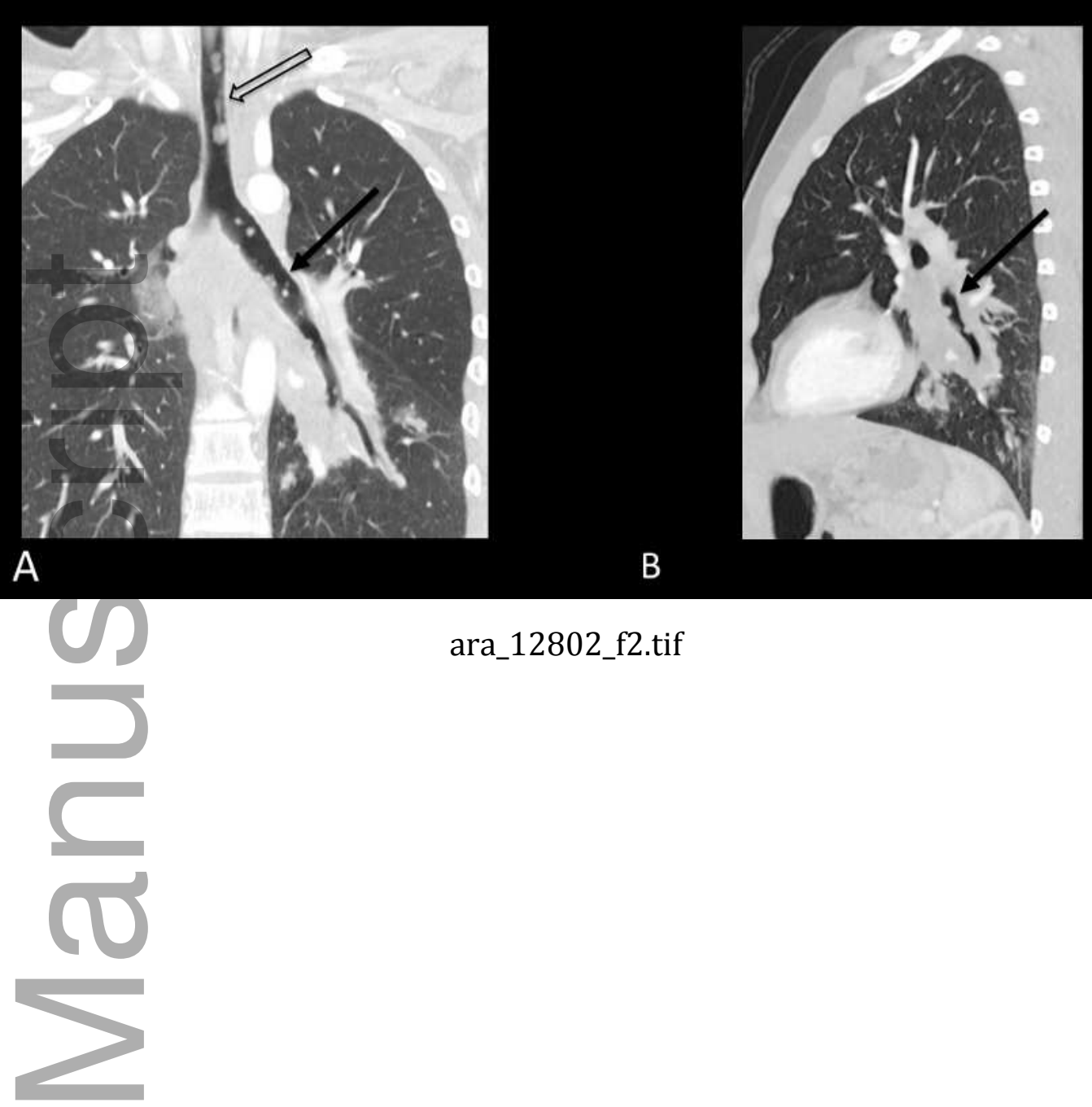

ara_12802_f2.tif

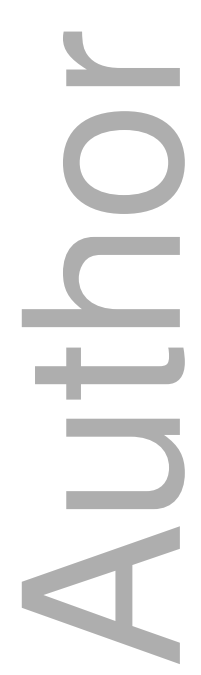

This article is protected by copyright. All rights reserved 

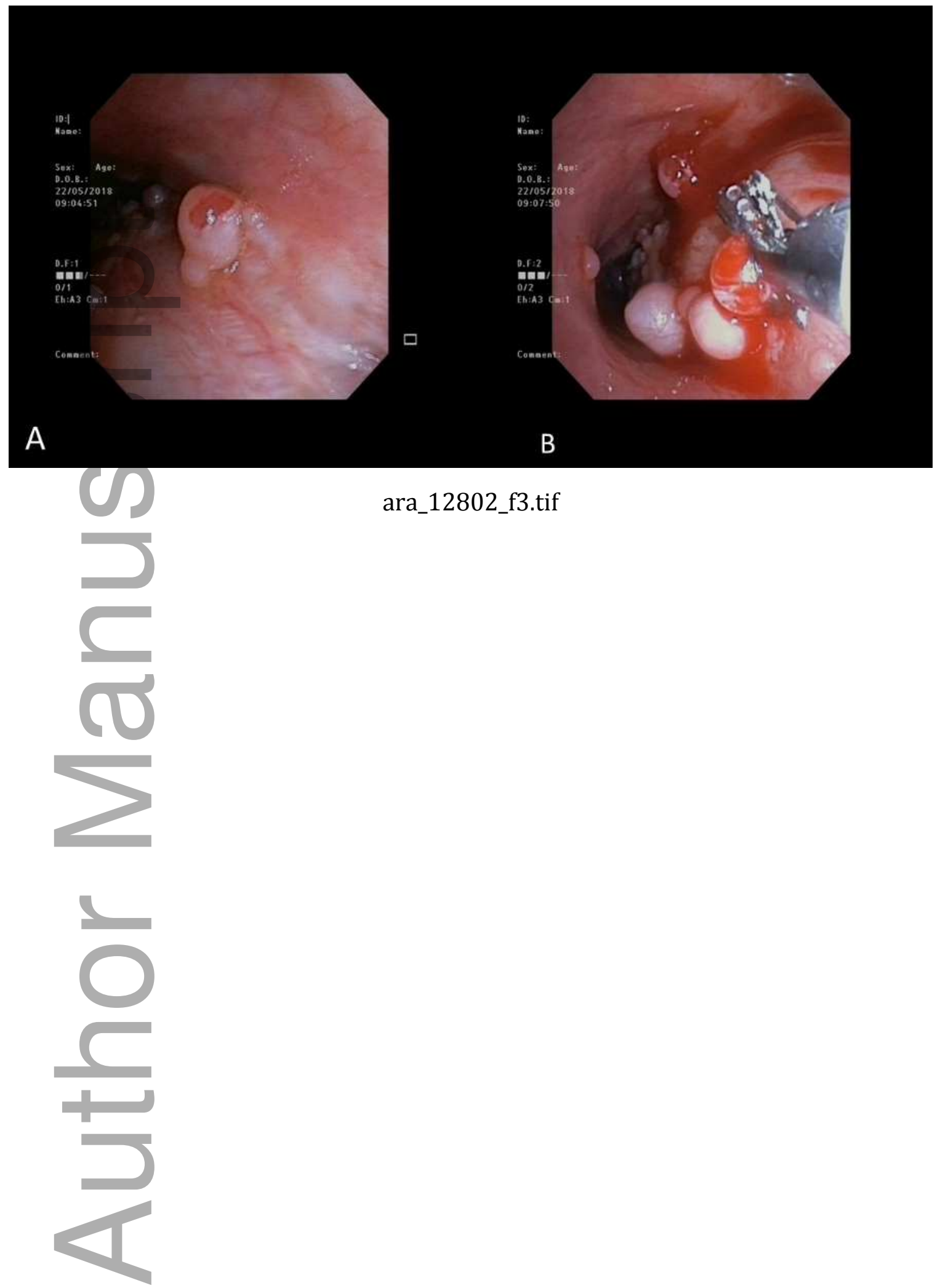

This article is protected by copyright. All rights reserved 

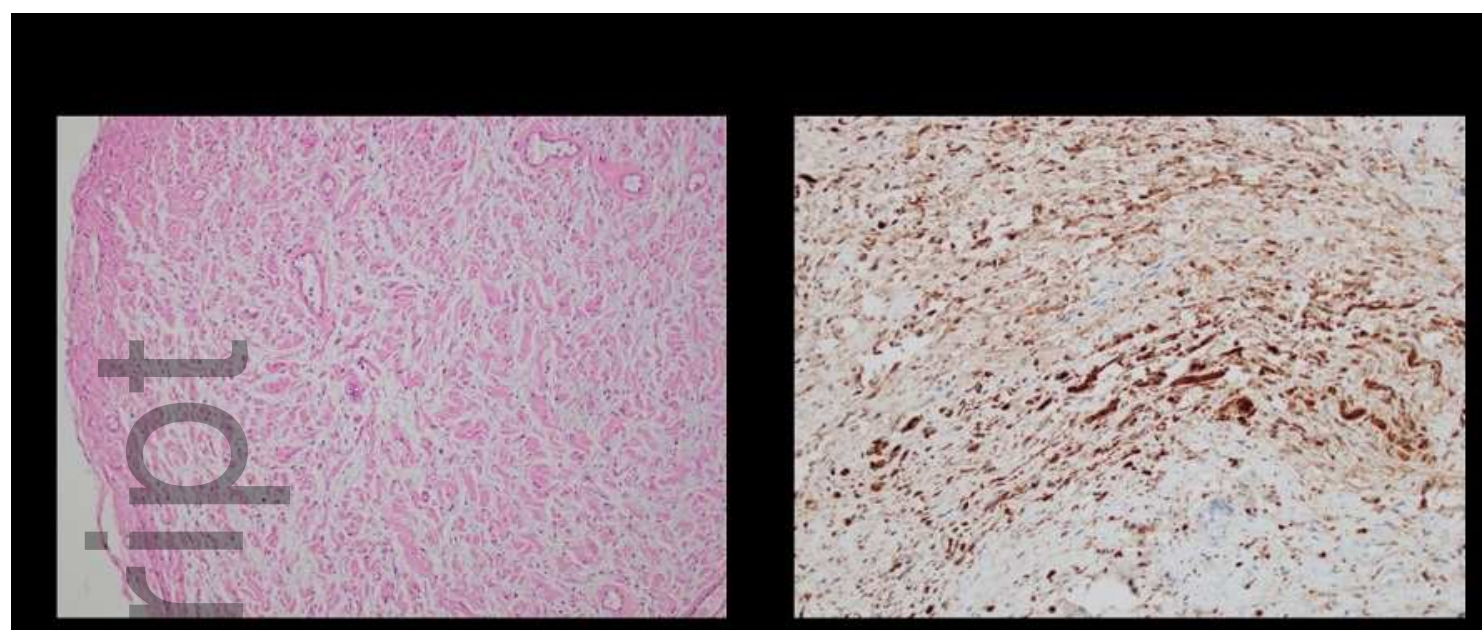

A

B

ara_12802_f4.tif

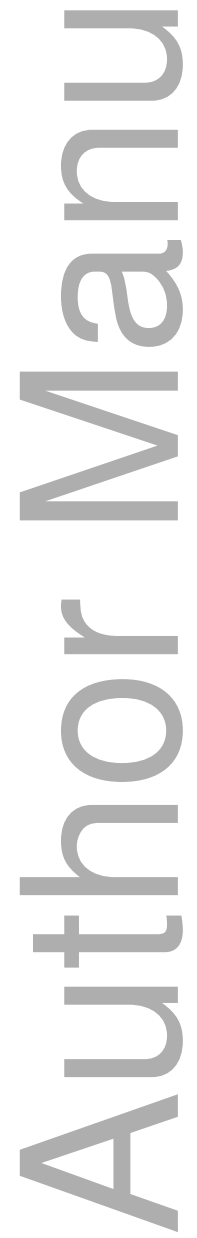

This article is protected by copyright. All rights reserved 


\section{University Library}

\section{- M I I N E R VA \\ A gateway to Melbourne's research publications}

Minerva Access is the Institutional Repository of The University of Melbourne

Author/s:

Pascoe, HM;Antippa, P;Irving, L;Christie, M;McCusker, MW

Title:

Rare manifestation of Neurofibromatosis type 1: A plexiform neurofibroma involving the mediastinum and lungs with endobronchial neurofibromata

Date:

2019-02-01

Citation:

Pascoe, H. M., Antippa, P., Irving, L., Christie, M. \& McCusker, M. W. (2019). Rare manifestation of Neurofibromatosis type 1: A plexiform neurofibroma involving the mediastinum and lungs with endobronchial neurofibromata. JOURNAL OF MEDICAL IMAGING AND RADIATION ONCOLOGY, 63 (1), pp.76-78. https:// doi.org/10.1111/1754-9485.12802.

Persistent Link:

http://hdl.handle.net/11343/284528 